\title{
Pharmacogenomics: A Step towards Advancing Clinical Trials
}

\section{Prashant Pandya*}

Reliance Life Sciences, Mumbai, India

Pharmacogenomics testing is a step towards advancing clinical trials, new product development and clinical practice. It permit drugs to be made tailor made for individual and studied as per generic makeup because some genes are responsible for drug effect. This will help to create personalized medicine with grater efficacy and safety by understanding genetic makeup of patients.

Our body has millions of genes. Testing of Drug-Gene is called as "Pharmacogenomics". Effect of Gene is studied after administration of drug during clinical trial. Genetic information is used to study the individual response as drugs are available for all but doesn't give similar response so it is difficult to know who will benefit or who will experience adverse drug reaction. Pharmacogenomics will help to make clinical decision based on genetics and accordingly dosage or different drug will be selected [1-7].

Pharmacogenomics allow early identification of signals of predictive information, it doesn't improve efficacy but provide useful information to the developers that who are likely to be responder and thus overall improve the drug development speed in clinical trials (Figure 1).

\section{Below is the Limitation of Pharmacogenomics Testing in Clinical Testing}

- One single test can't serve the purpose for all.

- Pharmacogenomic testing is not currently available for all medications as human share around $99.5 \%$ genomes and remaining $0.5 \%$ differ and responsible for our susceptibility to disease and drug response.

- It is expensive and time consuming to do such testing.

- It is difficult to extrapolate such testing in healthcare setting.

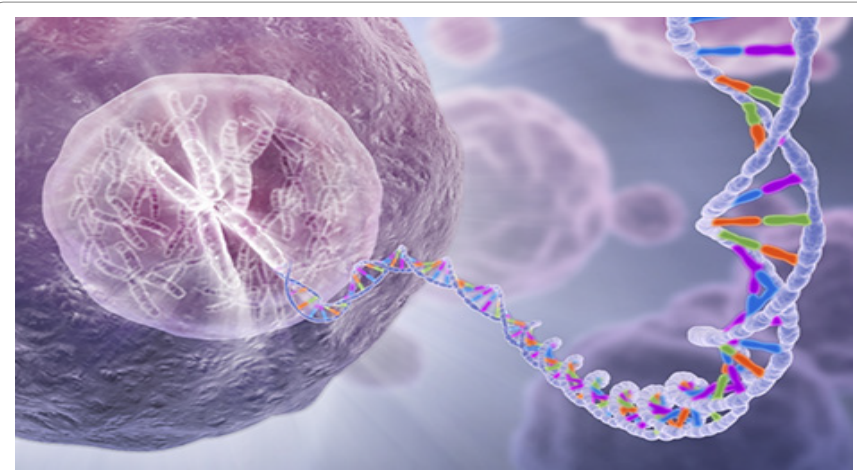

Figure 1: Individualized medicine (http://mayoresearch.mayo.edu/center-forindividualized-medicine/).
- Drug response is also affected by interacting genetic and environmental factors.

- Many times multiple genetic variants are responsible for the response.

\section{Conclusion}

- People respond differently to various medicines. With better understanding of disease help to develop efficient treatment. Pharmacogenomics testing will help in future to develop tailored made drugs, a form of personalized medicine having very less adverse drug reactions and help to identify drug that will best treat disease.

- It is advisable to include pharmacogenomics during early phase clinical trials which help to reduce overall development time and drug can be market earlier by doing clinical trial on less subjects.

\section{References}

1. Adams J (2008) Pharmacogenomics and personalized medicine. Nat Educ 1 194.

2. Goldstein DB, Tate SK, Sisodiya SM (2003) Pharmacogenetics goes genomic. Nat Rev Genet 4: 937-947.

3. Ingelman-Sundberg M, Oscarson M (1999) Polymorphic human cytochrome P450 enzymes: An opportunity for individualized drug treatment. Trends Pharmacol Sci 20: 342-349

4. Ohashi W, Mizushima H, Tanaka H (2008) Economic Advantage of Pharmacogenomics-Clinical Trials with Genetic Information, IOS Press.

5. O'Donnell PH, Stadler WM (2012) Pharmacogenomics in Early-Phase Oncology Clinical Trials: Is There a Sweet Spot in Phase II? AACR.

6. Warner AW, Bienfait KL, Bledsoe M, Burckart G (2013) Improving Clinical Trial Sampling for Future Research. Pharmacogenomics 14: 103-112

7. Rioux PP (2000) Clinical trials in pharmacogenetics and pharmacogenomics: methods and applications. Am J Health Syst Pharm 57: 887-898.

*Corresponding author: Dr. Prashant Pandya, Reliance Life Sciences, Mumbai, India, Tel: 91 9967017172; E-mail: prashant.pandya@relbio.com

Received March 28, 2017; Accepted March 29, 2017; Published April 05, 2017

Citation: Pandya P (2017) Pharmacogenomics: A Step towards Advancing Clinical Trials. J Pharmacogenomics Pharmacoproteomics 8: e157. doi: 10.4172/2153$0645.100 \mathrm{e} 157$

Copyright: ( 2017 Pandya P. This is an open-access article distributed under the terms of the Creative Commons Attribution License, which permits unrestricted use, distribution, and reproduction in any medium, provided the original author and source are credited. 